\title{
The ORBITA trial: A point of view
}

\author{
Vitor Dornela de Oliveira ${ }^{1}$, Fernando Rabioglio Giugni ${ }^{1}$, Eduardo Bello Martins ${ }^{2}$, Diogo Freitas Cardoso de Azevedo², \\ Eduardo Gomes Lima ${ }^{2 *} \odot$, Carlos Vicente Serrano Júnior ${ }^{2}$ \\ ${ }^{1}$ Cardiology Resident Physician, Faculdade de Medicina da Universidade de São Paulo (FMUSP), São Paulo, SP, Brazil \\ ${ }^{2}$ Department of Atherosclerosis, Instituto do Coração do Hospital das Clínicas da FMUSP (InCor-HC-FMUSP), São Paulo, SP, Brazil
}

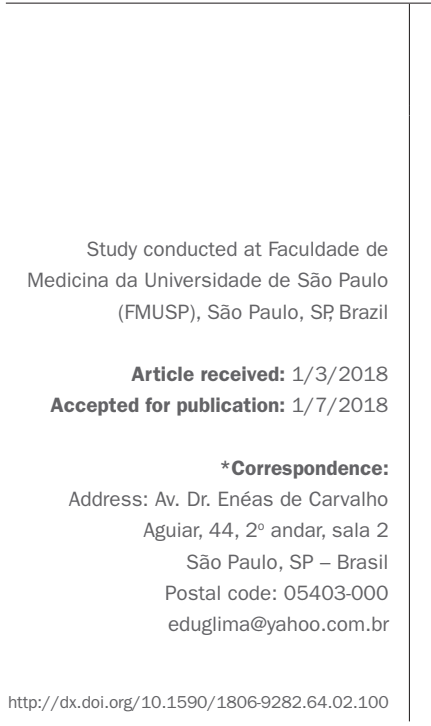

\section{SUMMARY}

Treatment of stable coronary artery disease (CAD) relies on improved prognosis and relief of symptoms. National and international guidelines on CAD support the indication for revascularization in patients with limiting symptoms and refractory to drug treatment. Previous studies attested the efficacy of angioplasty to improve angina as well as the functional capacity of patients with symptomatic stable CAD. The ORBITA trial, recently published in an international journal, showed no benefit in terms of exercise tolerance compared to a placebo procedure in a population of single-vessel patients undergoing contemporary percutaneous coronary intervention. In this point of view article, the authors discuss the ORBITA trial regarding methodological issues, limitations and clinical applicability.

Keywords: Coronary Artery Disease. Percutaneous Coronary Intervention. Stents. Stable Angina.
Treatment of stable coronary artery disease (CAD) relies on improved prognosis and relief of symptoms. National and international guidelines on CAD support the indication for revascularization in patients with limiting symptoms and refractory to drug treatment. ${ }^{1-3}$

In this scenario, percutaneous coronary intervention (PCI) is often performed, especially in single- or multivessel patients with a disease of lesser angiographic complexity (SYNTAX Score $\leq 22$ ). ${ }^{2}$ It is estimated that more than 500,000 angioplasties are performed annually in Europe and the USA, most of which not clearly indicated. ${ }^{4}$

One of the first studies evaluating the role of PCI in symptomatic relief was the Angioplasty Compared to Medicine (ACME) trial in 1992. It showed a lower prevalence of angina and greater tolerance to exercise in patients undergoing angioplasty compared to those who remained under exclusive drug treatment. ${ }^{5}$ Similarly, the Clinical Outcomes Using Revascularization and Aggressive Drug Evaluation (COURAGE) trial, composed predominantly of oligosymptomatic and multivessel patients, also revealed symptomatic relief in the group undergoing PCI with conventional stenting after 30 days, but this benefit was not sustained after three years of follow-up. ${ }^{6}$ Recently, the publication of three-year follow-up data from the FAME 2 study reported less angina in the PCI group compared to the group undergoing drug therapy.
There was no clinical trial assessing the possible "placebo effect" of angioplasty. Based on this, a group of UK researchers designed a specific study to compare PCI versus a "placebo procedure." That is the ORBITA trial, a multicenter, randomized, double-blind clinical trial, including patients $18-85$ years of age, single-vessels, with preserved left ventricular systolic function, without unprotected left main lesion and who presented with symptoms (angina according to the Canadian Cardiovascular Society classification I-III, or anginal equivalent). ${ }^{8}$ The results were recently published in The Lancet. ${ }^{4}$

It is important to emphasize that this is a low-risk single-vessel population, with a small number of diabetics (18\%) and without left ventricular dysfunction. Although all patients in the study had symptoms, only a minority (39\%) suffered from limiting angina (CCS III). The primary endpoint analyzed was the difference between the increases in exercise time in both groups. Secondary endpoints were change in peak $\mathrm{VO} 2$; change in time for $\mathrm{ST}$ segment decline of $1 \mathrm{~mm}$; improvement of angina according to the CCS classification; questionnaires of angina and quality of life (Seattle Angina Questionnaire and EQ-5D-5L, respectively); Duke score for exercise testing, and change in echocardiogram with dobutamine stress.

The study consisted of two follow-up phases. First, the patients were followed for six weeks in a period of 
clinical optimization, with titration of anti-anginal medications by telephone consultations. After this time interval, 200 patients remained symptomatic and were included for analysis of the results. They all underwent coronary angiograms, with randomization performed during the procedure. A total of 105 subjects were randomized to angioplasty and the remaining 95 were maintained in the placebo group.

Measurements of fractional flow reserve (FFR) and immediate wave-free ratio (IFR) were taken from all patients. All angioplasty procedures were performed using second-generation drug-eluting stents. The median angiographic epicardial stenosis among study participants was $85.7 \%$ (77.4-93.0). Median FFR, in turn, was 0.72 (0.57-0.81). Fifty-seven (57) patients (29\%) had an FFR value greater than 0.80 , and 64 of them (32\%) had IFR greater than 0.89 . We must keep in mind that FFR $>0.82$ or iFR > 0.92 was found in $25 \%$ of patients in the PCI group, which indicates lesions with no functional impairment and no formal recommendation for revascularization. After PCI, there was improvement in the median values of FFR and IFR (0.90 and 0.94, respectively). A total of four patients in the placebo group (4.2\%) required angioplasty due to complications associated with the coronary angiogram.

Study blinding was very well done, which was a merit of the researchers. The exams (exercise test, echocardiogram and catheterization) were performed by professionals who were not part of the research group. Neither patients nor researchers knew the group to which each individual belonged. During catheterization, patients were sedated and remained with headphones throughout the procedure. This fact ensures that the placebo effect has in fact been eliminated from the analysis of the results.

Patients were followed for six weeks after the procedure (angioplasty or placebo). The exams and questionnaires analyzed in the outcomes were performed before the catheterization procedure and after the follow-up period. There was no statistically significant difference in any of the outcomes analyzed, except for echocardiography with pharmacological stress, favoring angioplasty $(\mathrm{p}=0.0011)$.

Although it was a very well-designed study, with enviable methodology and blinding, some criticism should be considered. First, this was a low-risk population (singlevessel disease, without ventricular dysfunction), which prevents the extrapolation of study results to the other spectra of the disease. It is also important to note that patients were poorly symptomatic with CCS I-II angina in most cases, and that approximately one-third of the patients did not even have a functionally significant ob- struction based on FFR and IFR measures. In addition, the DEFER (Deferral Versus Performance of PTCA [percutaneous transluminal coronary angioplasty] in Patients Without Documented Ischemia) trial, a prospective and randomized study, clearly demonstrated that the longterm prognosis of patients with FFR $>0.75$ and intermediate lesions not treated with angioplasty is excellent (risk of cardiac death or myocardial infarction $<1 \%) .{ }^{9}$ It is noteworthy that the follow-up time in the ORBITA trial was short, and difficulties regarding drug adherence in the long-term could be considered. Once in this trial there was an average of approximately three anti-anginal drugs, a longer follow-up time would be necessary for a better comparison between treatment strategies.

It is a fact that the ORBITA is not the first study to reveal the ineffectiveness of angioplasty in promoting symptomatic improvement or improvement of exercise tolerance in specific subpopulations in the context of stable CAD. A subanalysis of the BARI-2D trial evaluated the health status and symptoms of patients randomized to revascularization or drug treatment. ${ }^{10}$ In the study, patients treated with surgical revascularization showed improvement of symptoms, which did not occur among those who underwent angioplasty in a long-term followup. Another clinical trial conducted by Hambrecht et al. compared ICP with physical rehabilitation and showed better tolerance to exercise in the group treated with physical rehabilitation alone. ${ }^{11}$ Finally, a meta-analysis published in 2013 including a total of 4,064 patients with objective documentation of ischemia failed to demonstrate improved angina among patients undergoing PCI compared with those on drug therapy. ${ }^{12}$

While evaluating the body of available evidence, it must be kept in mind that angina is a symptom with complex and multifactorial pathophysiology, so the reduction of coronary flow caused by stenosis in the epicardial artery is not the only factor involved with the pain (Figure 1). The regulation of this flow also depends on the preservation of endothelial function and microvasculature. Furthermore, nonvascular factors such as myocardial hypertrophy can compromise blood flow to a given territory. Angina is often a difficult symptom to characterize, being greatly influenced by subjective factors. Also, thoracic pain of diverse etiologies may occur concomitantly, reducing the beneficial effect of revascularization.

A possible conclusion is that the ORBITA trial was daring to test the concept of the placebo effect of PCI; however, we must be careful about its results. PCI adequately fulfilled its role of resolving epicardial vessel obstruction, which is clear with improved FFR/IFR values 


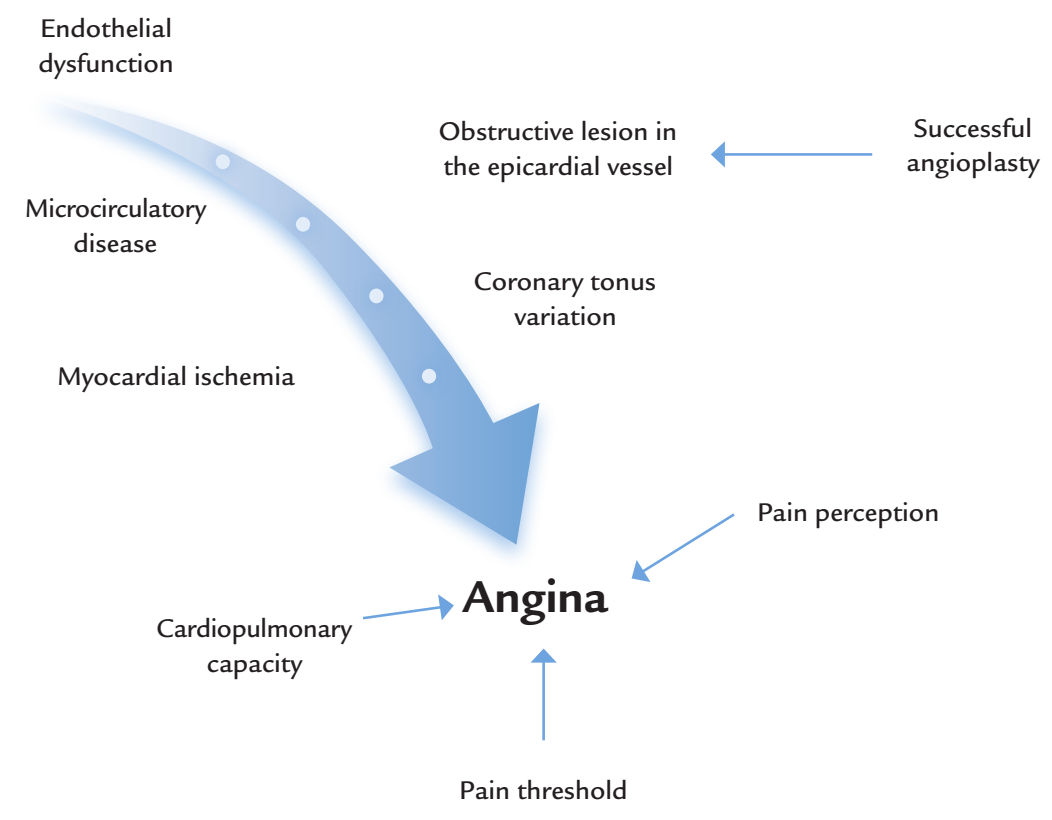

FIGURE 1 Complexity of the processes that culminate in the occurrence of angina accompanied by factors that modulate its intensity. Note that successful angioplasty suppresses only one of the steps in this process.

and stress echocardiography. Nevertheless, revascularization of the epicardial artery did not necessarily translate into an improvement in angina, much less a better tolerance to exercise, which is understandable given the multifactorial nature of these variables.

Much is debated whether the ORBITA trial will impact the guidelines for management of stable CAD. Considering the limitations mentioned, as well as the profile of patients included in the ORBITA, we believe that little will change in clinical practice, since the current guidelines would not even suggest revascularization for many patients included in the study. In any case, the study leads the medical community to reflect on the indication of intervention in the population with chronic $\mathrm{CAD}$, always pondering the real benefits, risks and expectations of both the patient and the physician indicating the procedure. Understanding the pathophysiology of the disease and adequately interpreting the clinical evidence are fundamental steps in this process.

\section{Conflict of interest}

The authors declare no conflicts of interest.

\section{Resumo}

Estudo ORBITA: um ponto de vista
O tratamento da doença arterial coronariana (DAC) estável se baseia na melhora do prognóstico e alívio de sintomas. Diretrizes nacionais e internacionais sobre a DAC respaldam a indicação de revascularização em pacientes com sintomas limitantes e refratários ao tratamento medicamentoso. Estudos prévios atestavam a eficácia da angioplastia na melhora da angina, bem como na capacidade funcional de pacientes com DAC estável sintomática. O estudo ORBITA, publicado recentemente em revista internacional, mostrou em população de uniarteriais submetidos a angioplastia com stent farmacológico ausência de benefício na tolerância ao exercício quando comparado a procedimento placebo. No presente ponto de vista, os autores discutem o trabalho em questão quanto a método, limitações e aplicabilidade clínica.

Palavras-chave: Doença Arterial Coronariana. Angioplastia. Stents. Angina Estável.

\section{References}

1. Cesar LA, Ferreira JF, Armaganijan D, Gowdak LH, Mansur AP, Bodanese LC, et al. Diretriz de doença coronária estável. Arq Bras Cardiol. 2014; 103(2 Suppl 2):1-59.

2. Montalescot G, Sechtem U, Achenbach S, Andreotti F, Arden C, Budaj A, et al. 2013 ESC guidelines on the management of stable coronary artery disease: the Task Force on the management of stable coronary artery disease of the European Society of Cardiology. Eur Heart J. 2013; 34(38):2949-3003. 
3. Patel MR, Calhoon JH, Dehmer GJ, Grantham JA, Maddox TM, Maron DJ, et al. ACC/AATS/AHA/ASE/ASNC/SCAI/SCCT/STS 2017 Appropriate use criteria for coronary revascularization in patients with stable ischemic heart disease: a report of the American College of Cardiology Appropriate Use Criteria Task Force, American Association for Thoracic Surgery, American Heart Association, American Society of Echocardiography, American Society of Nuclear Cardiology, Society for Cardiovascular Angiography and Interventions, Society of Cardiovascular Computed Tomography, and Society of Thoracic Surgeons. J Am Coll Cardiol. 2017; 69(17):2212-41.

4. Al-Lamee R, Thompson D, Dehbi HM, Sen S, Tang K, Davies J, et al. Percutaneous coronary intervention in stable angina (ORBITA): a doubleblind, randomised controlled trial. Lancet. 2018; 391(10115):31-40.

5. Parisi AF, Folland ED, Hartigan P. A comparison of angioplasty with medical therapy in the treatment of single-vessel coronary artery disease. Veterans Affairs ACME Investigators. N Engl J Med. 1992; 326(1):10-6.

6. Weintraub WS, Spertus JA, Kolm P, Maron DJ, Zhang Z, Jurkovitz C, et al. Effect of PCI on quality of life in patients with stable coronary disease. N Engl J Med. 2008; 359(7):677-87.

7. Fearon WF, Nishi T, De Bruyne B, Boothroyd DB, Barbato E, Tonino P, et al. Clinical outcomes and cost-effectiveness of fractional flow reserveguided percutaneous coronary intervention in patients with stable coronary artery disease: three-year follow-up of the FAME 2 Trial (Fractional Flow Reserve versus Angiography for Multivessel Evaluation). Circulation. 2017; 136:00-00

8. Campeau L. Letter: Grading of angina pectoris. Circulation .1976; 54(3):522-3

9. Pijls NHJ, van Schaardenburgh P, Manoharan G, Boersma E, Bech JW, van't Veer $\mathrm{M}$, et al. Percutaneous coronary intervention of functionally nonsignificant stenosis: 5- year follow-up of the DEFER study. J Am Coll Cardiol. 2007; 49(21):2105-11.

10. Brooks MM, Chung SC, Helmy T, Hillegass WB, Escobedo J, Melsop KA, et al. Health status after treatment for coronary artery disease and type 2 diabetes mellitus in the Bypass Angioplasty Revascularization Investigation 2 Diabetes trial. Circulation. 2010; 122(17):1690-9.

11. Hambrecht R, Walther C, Möbius-Winkler S, Gielen S, Linke A, Conradi $\mathrm{K}$, et al. Percutaneous coronary angioplasty compared with exercise training in patients with stable coronary artery disease. Circulation. 2004; 109(11):1371-78

12. Stergiopoulos K, Boden WE, Hartigan P, Möbius-Winkler S, Hambrecht R, Hueb W, et al. Percutaneous coronary intervention outcomes in patients with stable obstructive coronary artery disease and myocardial ischemia: a collaborative meta-analysis of contemporary randomized clinical trials. JAMA Intern Med. 2014; 174(2):232-40. 